cases but we discovered interstitial lung diseases (12.7\%), pleurisy $(7.3 \%)$, pleural nodule and mediastinal enlargement $(3.6 \%)$ and pneumopathy $(1.8 \%)$. The same appearences were described in the CT scann normal in $18.5 \%$ but in different proportions: adenopathies (25.9\%), interstitial lung abnormalities $(14.8 \%)$, fibrosis $(11.1 \%)$, bronchiectasis $(7,4 \%)$ and bronchi dilatation, pleurisy, nodule and mediastinal enlargement $(3.7 \%)$. Respiratory functional exploration were normal in $69.2 \%$ obstructive lung disease and restrictive pulmonary disease were found within $11.5 \%$ of the patients.

Conclusions: Improvement of the knowledge of these diseases will improve the care before the appearance of complications.

Disclosure of Interest: None declared

DOI: 10.1136/annrheumdis-2017-eular.6207

\section{AB0981 CLINICAL FEATURES OF 28 CASES OF LIMB RESTRICTED VASCULITIS AND FASCIITIS}

H. Mukoyama, K. Nishimura, R. Saito, Y. Nakamura, T. Nagamoto, T. Yokota. Department of Endocrinology and Rheumatology, Kurashiki Central Hospital, Kurashiki, Okayama, Japan

Background: We sometimes experience the cases with fever and muscle pain of lower limbs without any other specific features. There are sporadic case reports of eosinophilic fasciitis and limb restricted vasculitis. However, few reports compare and discuss such cases.

Objectives: To describe the clinical features, MRI findings, histopathology, diagnosis and response to treatment of these cases.

Methods: We retrospectively analyzed the clinical features of 28 patients who were admitted to our hospital because of fever and muscle pain of lower limbs from 2004 to 2016 .

Results: Among the 28 patients, 17 were vasculitis syndrome; eleven were limb restricted small vessel vasculitis (LrSvv), six were microscopic polyangiitis (MPA). Seven were fasciitis; three were eosinophilic fasciitis, three were diffuse fasciitis without eosinophilia and one was tuberculous fasciitis. One was relapsing polychondritis, one was Behçet's disease and the other two were myalgia without specific diagnosis. In our study, average age was $57.5 \pm 19.9$ years old and older than in previously reported cases of limb ristricted vasculitis ${ }^{1,2}$. Sixteen were female, twelve were male. Abnormal MRI findings in non-infectious fasciitis and vasculitis syndrome were bilateral. Tuberculous fasciitis showed specifically abnormal intensity and fluid collection in unilateral thigh. Unilateral lesion and fluid collection may indicate infectious disease and bilateral lesion may indicate autoimmune or autoinflammatory diseases. MRI of vasculitis syndrome and fasciitis showed hyperintense T2-weighted signals in muscles of either legs, or thighs, or both. $(n=3)$, MPA $(n=1)$ and fasciitis $(n=3)$. On MRI scan, abnormal fascial signal intensity was seen in all the patients with fasciitis and $6(40 \%)$ with vasculitis syndrome. It was difficult to differentiate between vasculitis and fasciitis by MRI findings. Muscle biopsy was performed in 25 patients. In most cases, we performed en bloc biopsy, including muscle, fascia, skin and subcutaneous tissue. MRI was useful to determine the location of biopsy. All patients were treated with glucocorticoids. Immunosuppressive agents (azathioprine, $n=10$; methotrexate, $\mathrm{n}=5$; cyclophosphamide, $\mathrm{n}=1$; tacrolimus, $\mathrm{n}=1$ ) were added in 15 patients and anti-tuberculous drugs in one. None of the 11 patients with LrSvv showed positive blood tests of anti-neutrophil cytoplasmic antibody or developed any other organ involvement during follow-up period (median 96 months; range 3-125). They responded well to glucocorticoid therapy (oral prednisolone $0.5-0.6 \mathrm{mg} / \mathrm{kg} /$ day or intravenous methylprednisolone at doses of $1 \mathrm{~g} /$ day). Recurrence rate of LrSvv patients was $0 \%$, although that of MPA patients was $50 \%(n=3)$. In four patients with LrSvv, treatment was ceased and they achieved drug-free remission. There were no apparent differences between the patients who achieved drug-free remission and who didn't.

Conclusions: MRI and muscle biopsy were useful for diagnosis of disease with fever and muscle pain of lower limbs.

References:

[1] Gallien S, et al. Ann Rheum Dis 2002;61:1107-9.

[2] Khellaf M, et al. Ann Rheum Dis 2007;66:554-556.

Disclosure of Interest: None declared

DOI: 10.1136/annrheumdis-2017-eular.4169

\section{AB0982 ANALYSIS OF THE TREATMENT EFFICACY FOR RETROPERITONEAL FIBROSIS - A CASE SERIES. SUSPICION OF ERDHEIM-CHESTER DISEASE IN A PATIENT WITH AN INITIAL DIAGNOSIS OF RETROPERITONEAL FIBROSIS, REFRACTORY TO STANDARD TREATMENT}

J. Koblowski ${ }^{1}$, A. Juszkiewicz ${ }^{1}$, M. Kania-Pudło ${ }^{2}$, W. Tlustochowicz ${ }^{1} .{ }^{1}$ Internal Medicine and Rheumatology; ${ }^{2}$ Radiology, Military Institute of Medicine, Warsaw, Poland

Background: Retroperitoneal fibrosis (RPF) is a rare disorder characterized by the development of fibrotic tissue in the retroperitoneum involving the abdominal aorta, iliac arteries and ureters. Erdheim-Chester disease (ECD) is a rare, non-Langerhans histiocytosis. Symptoms of ECD often resemble retroperitoneal fibrosis.

Objectives: Evaluation of standard treatment efficacy in 13 consecutive RPF patients. Revision of the diagnosis in patients unresponsive to standard therapy. Methods: A retrospective analysis of 13 consecutive RPF patients $(10$ males and 3 females) treated in our department since 2008 was performed. All patients were treated with tapered dose of steroids combined with an immunosuppressive agent (cyclophosphamide in 4, azathioprine in 9, methotrexate in 6 , hydroxychloroquine in 5 patients). Urologic interventions were undertaken as necessary.

Results: The treatment was effective in 10 patients: reduction of the retroperitoneal mass in computed tomography (CT) and normalization of the laboratory tests, including markers of inflammation and creatinine concentration. No improvement was found in 3 patients. However, in a further diagnostic work-up the diagnosis of RPF was maintained only in one of these 3 patients. In the second pateint an ANCA-asssotiated vasculitus was ultimately diagnosed. The third patient was treated with a combination of steroids and cyclophosphamide without any radiological improvement. However, the revision of CTs revealed the presence of changes typical of Erdheim-Chester disease.

Conclusions: The standard treatment (based on a combination of steroids and immunosuppressive drugs) is efficient in most partients with RPF. In refractory cases an alternative diagnosis, such as systemic vasculitis or Erdheim-Chester disease, should be taken into account.

References:

[1] Diamond El et al. Consensus guidelines for the diagnosis and clinical management of Erdheim-Chester disease. Blood. 2014 Jul 24;124(4):483-92.

[2] Kermani TA et al. Idiopathic retroperitoneal fibrosis: a retrospective review of clinical presentation, treatment, and outcomes. Mayo Clin Proc. 2011 Apr;86(4):297-303.

Disclosure of Interest: None declared

DOI: 10.1136/annrheumdis-2017-eular.5960

\section{AB0983 MEFV MUTATIONS IN ARMENIAN PATIENTS WITH SYSTEMIC AUTOIMMUNE DISEASES}

K. Ginosyan, A. Beglaryan ${ }^{1,1}$, V. Vardanyan. Internal Medicine, Yerevan State Medical University, Yerevan, Armenia

Background: The systemic diseases of connective tissue have autoimmune mechanism in development. While autoimmunity involves adaptive immune activation, autoinflammation involves innate immune activation. The prototype of autoinflammatory diseases is familial Mediterranean fever (FMF), which is the global medical problem for Armenian ethnos on the whole, affecting $1-2 \%$ of population.

Objectives: The aim of this study was investigation of MEFV mutations and their possible influence on the systemic diseases in Armenian patients.

Methods: We have examined 183 patients with FMF. All patients with FMF fulfilled Tel-Hashomer FMF diagnostic criteria. Molecular-genetic detection of 12 MEFV mutations common for Armenians carried out in Medical Genetic Centre of Armenia. In 49 patients one of autoimmune systemic diseases was diagnosed: in 24 patients- seronegative spondyloarthropathy (SNSA), in 23 - systemic lupus erythematosus (SLE), 1 patient developed Sjogren's disease and 1- systemic sclerosis.

Results: In the SNSA group from 24 patients 16 were male, 8 were female, the mean age of patients was $35,4 \pm 12,2$. The mean age at the beginning of the disease was $14,91 \pm 12,6$. In all cases the symptoms of FMF were preceded symptoms of arthritis. Unilateral sacroilitis was revealed in 6 patients, bilateral sacroilitis-in 18 patients. The limitation of lumbar motion was assessed by Schober's test. 7 patients with Schober's test $1-2 \mathrm{~cm}$ had bilateral sacroiliits grade III-IV and fulfilled the modified New York criteria for ankylosing spondylitis. HLA B-27 was examined in 7 patients. In 5 cases it was negative, and in 2 cases -positive. MEFV gene analyses were carried out in 21 cases: 7 patients had one heterozygote mutations: 6-M694,1-M680I; 5 patients -M694V/M694V, 9 patients had compound heterozygote mutations: 5- M694V/V726A, 3 - M694V/E148Q, 1 $\mathrm{M} 680 \mathrm{I} / \mathrm{E} 148 \mathrm{Q}$. So, the prevalent mutation was M694V.

In SLE group from 23 patients female were 21 (91.3\%), male - 2 (8.7\%). Mean age of patients was $37.4 \pm 2.5$ years. The beginning of FMF was earlier than SLE. The activity of SLE estimated by SLEDAI index was significant lower than in SLE without FMF. SLE co-occurring with FMF had mild duration than classic lupus according to both clinical and laboratory findings including serological markers of SLE -ANA, anti-dsDNA. The prevalent mutation was M694V - 44.6\%; V726A composed $21.7 \%$, M680I-9.8\%. Most common variations with M694V were followings:M694V/M694V,M694V/V726A,M694V/N

Conclusions: A remarkable overlap was highlighted between FMF and SLE: both diseases have such common features as arthralgia, myalgia, arthritis, fever, skin involvement, serositis and renal involvement. It is likely, that the moderation in disease phenotype and peculiar disease characteristics observed in patients with both SLE and FMF are related to MEFV. MEFV mutations appear to modify SLE phenotype. Sacroilitis may be seen more frequently in FMF patients than expected. On the other hand, FMF must be kept in mind if patients not responding to the usual therapeutic interventions for sacroiliitis.

References:

[1] Doria Z., Zen M., Bettio S., et al. Autoinflammation and autoimmunity:bridging the divide. Autoimmune Rev.2012 Nov;12 (1): 22-30.

[2] Cattan D. MEFV Mutation Carriers and Diseases other than FMF;Proved and Non-proved Associations; Putative Biological Advantage. Curr. Drug Targets-Inflam.\&Allergy, 2005;4:105-112. 
Disclosure of Interest: None declared

DOI: 10.1136/annrheumdis-2017-eular.5109

\section{AB0984 TOCILIZUMAB MONOTHERAPY FOR POLYMYALGIA RHEUMATICA RESULTS OF 52-WEEK TREATMENT OF A PROSPECTIVE, SINGLE-CENTER, OPEN, SINGLE-ARM TRIAL}

K. Amano, K. Chino, Y. Okada, A. Shibata, A. Okuyama, T. Kurasawa, H. Takei, T. Kondo. Rheumatology and clinical immunology, Saitama Medical Center, Saitama Medical University, Kawagoe, Japan

Background: Polymyalgia rheumatic (PMR) is a chronic inflammatory rheumatic disease in the elderly people. Glucocorticoid (GC) is still definitely a mainstay for the treatment of PMR, but long-term GC therapy is a major risk factor of osteoporotic fractures, diabetes, hyperlipidemia, cardio-cerebral vascular events, glaucoma, etc. So GC-free treatment strategies for PMR are necessary for some patients with PMR. IL-6 is involved in the pathogenesis of PMR and quite a few case reports have already shown the efficacy of tocilizumab (TCZ) in PMR patients and some of them received TCZ monotherapy without GC.

Objectives: To assess the efficacy and safety of TCZ monotherapy for PMR Methods: Thirteen PMR patients (male 3, female 10) who had been diagnosed by 2012 ACR/EULAR classification criteria from Jan 2013 to Feb 2015 were enrolled in our study (IRB application No. 638, UMIN registration No. 000008812) after obtaining the written informed consent. TCZ $(8 \mathrm{mg} / \mathrm{kg})$ was administered biweekly for the first 2 months (5 infusions) and every 4 weeks thereafter for 40 weeks (total 48 weeks). ESR, CRP, patient's global health assessed by visual analog scale (VAS), PMR activity score were evaluated every 4 week prospectively and were evaluated at week 52. Remission was defined as PMR activity score less than 1.5.

Results: Baseline patients' characteristics revealed various kinds of comorbidities in 11 patients; hypertension in 7 , hyperlipidemia in 5 , diabetes mellitus in 3 , osteoporotic vertebral fractures in 2 , history of angina pectoris in 1, history of brain infarction in 1, history of hematemesis due to NSAID ulcer in 1 and glaucoma in one patient. Nine patients could complete this 52-week trial and could achieve remission at week 52 . Two patients discontinued TCZ because of no response at week 6 (No.1) and week 16 (No. 8) respectively. One patient (No.2), who were in clinical remission of PMR, dropped out from this study due to pemphigoid at week 50 and received GC therapy. Patient No. 12 abandoned TCZ at week 12 because of lung infiltrates although she was treated successfully with TCZ monotherapy, and she had been in remission without any treatment until week 52 . The other 3 drop-out patients could obtain remission with GC therapy at week 52 . There were no serious adverse events during 52-week treatment period.

Conclusions: TCZ mono-therapy was effective in most (9 out of 13) PMR patients although response was not so rapid as compared to GC. TCZ mono-therapy may be a good alternative therapy instead of GC for elderly patients with various comorbidities

\section{References:}

[1] Unizony S, et al.: Arthritis Care Res 2012; 64(11):1720-1729.

[2] Macchioni P, et al.: Aemin Arthritis Rheum 2013; 43(1): 113-118.

[3] Toussirot E, et al.: J Rheumatol 2016 43(1): 249-251.

[4] Leeb BF, et al.: Arthritis Rheum 2007; 57(5): 810-815.

Acknowledgements: We will thank Izumi Oshima, Takashi Kukita for data collection and management of this study.

Disclosure of Interest: K. Amano Grant/research support from: Chugai Pharnmaceutical Co.Ltd., K. Chino: None declared, Y. Okada: None declared, A. Shibata: None declared, A. Okuyama: None declared, T. Kurasawa: None declared, H. Takei: None declared, T. Kondo: None declared

DOI: 10.1136/annrheumdis-2017-eular.4525

\section{AB0985 METHOTREXATE AS INDUCTION OF REMISSION THERAPY FOR LOCALIZED MANIFESTATIONS OF IGG4-RELATED DISEASE}

L. Rovati $^{1}$, E. Della-Torre ${ }^{1}$, M. Lanzillotta ${ }^{1}$, E. Bozzalla Cassione ${ }^{1}$, E. Bozzolo ${ }^{1}$ C. Canevari ${ }^{2}$, M. Falconi ${ }^{3,4}$, L. Dagna ${ }^{1,4} .{ }^{1}$ Unit of Immunology, Rheumatology, Allergy and Rare Diseases; ${ }^{2}$ Unit of Nuclear Medicine; ${ }^{3}$ Pancreatic Surgery Unit, San Raffaele Scientific Institute; ${ }^{4}$ Università Vita-Salute San Raffaele, Milan, Italy

Background: Medium to high dose glucocorticoids represents the treatment of choice for inducing remission in IgG4-related disease (IgG4-RD) patients ${ }^{1}$. However, clinicians might prefer alternative equally effective drugs in clinical settings where long-term corticosteroids treatment is contraindicated, such as diabetes or osteoporosis. We recently reported the efficacy of methotrexate in maintaining glucocorticoids induced lgG4-RD remission ${ }^{2}$.

Objectives: To evaluate the efficacy of methotrexate as induction of remission therapy in selected cases of mild and localized IgG4-RD complicated by clinical scenarios that might advise against corticosteroids treatment.

Methods: Five patients with active untreated IgG4-RD were started on oral or subcutaneous methotrexate (up to 15-20 mg/week). Efficacy of methotrexate in inducing remission was assessed at 6 months by $18 \mathrm{~F}$-FDG PET/CT scan and by measuring the IgG4-RD Responder Index (RI) ${ }^{3}$ and circulating plasmablasts ${ }^{4}$. Partial response (PR) corresponded to an improvement of the IgG4-RD RI >2 points. Complete response (CR) corresponded to an IgG4-RD RI score $<3$.
Results: All patients were males with a mean age of 67 years (range 53-78). Two had pancreatic involvement; one had lymph node enlargement; one had pancreatic and lymph node involvement; one had pancreatic, aortic, submandibular gland and lymph node involvement. Patients with pancreatic involvement presented with increased serum amylases or abdominal discomfort; none had obstructive jaundice; all had overt diabetes. The mean IgG4-RD RI, serum IgG4 concentration and plasmablasts counts at baseline were $8(6-15), 483 \mathrm{mg} / \mathrm{dL}(136-983)$ and $3336 / \mathrm{mL}$ (330-9330/mL), respectively. All patients had increased $18 \mathrm{~F}-\mathrm{FDG}$ uptake on PET/CT scan within the affected organs. After 6 months of methotrexate, Patients 1, 2, and 3 were on CR with improved or normalized PET/CT findings, serum IgG4 and plasmablasts levels. Patient 5 achieved PR, showing improved 18F-FDG-PET/CT findings, normal plasmablasts level, but stable serum IgG4 concentration; after 10 months of methotrexate, persistence of disease activity prompted the introduction of glucocorticoids. Methotrexate was stopped in Patient 4 after 5 months because of nausea and vomiting; at 6 months he showed persistently increased plasmablasts count and 18F-FDG uptake on PET/CT, thus requiring a rescue therapy with glucocorticoids. (Table 1)

\begin{tabular}{|c|c|c|c|c|c|c|}
\hline & \multirow{2}{*}{\multicolumn{2}{|c|}{$\begin{array}{l}\text { Patient } n 1(M, 78) \\
\text { Type } 1 \text { AlP, artic, submandibular } \\
\text { gland, Iymph node involvement }\end{array}$}} & \multicolumn{2}{|c|}{ Patient $12(M, 67)$} & \multicolumn{2}{|c|}{ Patient $\pi 3(M, 70)$} \\
\hline & & & \multicolumn{2}{|c|}{ Type 1 AIP } & \multicolumn{2}{|c|}{$\begin{array}{l}\text { Type } 1 \text { AiP, iymph node } \\
\text { involvement }\end{array}$} \\
\hline & $\begin{array}{l}\text { Pre- } \\
\text { Treatment }\end{array}$ & $\begin{array}{c}6 \text { months (MTx } 20 \\
\mathrm{me} / \text { week) }\end{array}$ & Pre-Treatment & $\begin{array}{l}6 \text { months } \\
\text { (MT1/ 15 } \\
\text { me/week) }\end{array}$ & Pre-Treatment & $\begin{array}{l}6 \text { months } \\
(M M T 15 \\
\text { me/week) }\end{array}$ \\
\hline IgGA-RD RI & 15 & $2(C R)$ & 6 & $2(C R)$ & 9 & $1(C R)$ \\
\hline $\lg G 4$ (mg/dil) & 498 & 313 & 586 & 324 & 221 & 157 \\
\hline PBSS/mL & 2520 & 250 & 940 & 470 & 3560 & 130 \\
\hline \multirow[t]{4}{*}{ 18F-FDG.PET/CT } & $\begin{array}{l}\text { Increased } \\
\text { FDG activity } \\
\text { in all affected } \\
\text { organs except } \\
\text { Dancreas }\end{array}$ & $\begin{array}{l}\text { Decreased FDG } \\
\text { xctivity in } \\
\text { subrandibulat } \\
\text { glands; negative in } \\
\text { all the octher organs }\end{array}$ & $\begin{array}{l}\text { Increased FDG } \\
\text { activity in } \\
\text { pancreatic chead } \\
\text { and tail }\end{array}$ & $\begin{array}{l}\text { Partial } \\
\text { reduction in } \\
\text { pancreatic } \\
\text { FDG activity }\end{array}$ & $\begin{array}{l}\text { Increased FDG } \\
\text { activity in } \\
\text { pancreas and } \\
\text { hilar Iymph } \\
\text { nodes }\end{array}$ & $\begin{array}{l}\text { Negative in all } \\
\text { the involved } \\
\text { organs }\end{array}$ \\
\hline & \multicolumn{2}{|c|}{ Patient $n 4(M, 61)$} & \multicolumn{2}{|c|}{ Patient $45(M, 53)$} & & \\
\hline & \multicolumn{2}{|c|}{ Type 1 AlP } & \multicolumn{2}{|c|}{ Lymph node involvement } & & \\
\hline & Pre-Treatment & $\begin{array}{l}6 \mathrm{months} \text { (MTX } \\
15 \mathrm{mg} / \text { week) }\end{array}$ & $\begin{array}{l}\text { Pre- } \\
\text { Trestment }\end{array}$ & $\begin{array}{l}\text { months (MTX } \\
20 \mathrm{mg} / \text { week) }\end{array}$ & & \\
\hline IGGA-RD RI & 6 & NA & 6 & $3(\mathrm{PR})$ & & \\
\hline IBGA (medol) & 136 & NA & 973 & 819 & & \\
\hline PBS/mL & 330 & 880 & 9330 & 0 & & \\
\hline 18F-FDG-PET/CT & $\begin{array}{l}\text { Increased FDG } \\
\text { activity in } \\
\text { pancreatic chesd } \\
\text { and body }\end{array}$ & $\begin{array}{l}\text { Markedly } \\
\text { increased FDG } \\
\text { activity in } \\
\text { pancreatic head } \\
\text { and body }\end{array}$ & $\begin{array}{l}\text { Increased } \\
\text { nodal FDG } \\
\text { activity }\end{array}$ & $\begin{array}{l}\text { Decreased } \\
\text { nodal FDG } \\
\text { ctivity, but not } \\
\text { dimensional } \\
\text { eduction of the } \\
\text { lymph nodes }\end{array}$ & & \\
\hline
\end{tabular}

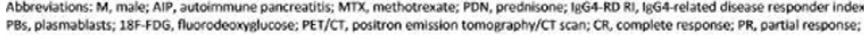
PBS, plasmablasts;
NA. not avoliable.

Conclusions: In localized forms of IgG4-RD with mild manifestations, methotrexate represents a promising alternative strategy for inducing disease remission, especially in the presence of contraindications to glucocorticoids.

References:

[1] Khosroshahi A, et al. International Consensus Guidance Statement on the Management and Treatment of IgG4-Related Disease. Arthritis Rheumatol. 2015.

[2] Della-Torre E, et al. Methotrexate for maintenance of remission in IgG4-related disease. Rheumatology (Oxford). 2015.

[3] Carruthers MN, et al. Development of an IgG4-RD Responder Index. Int J Rheumatol. 2012.

[4] Wallace ZS, et al. Plasmablasts as a biomarker for IgG4-related disease, independent of serum IgG4 concentrations. Ann Rheum Dis. 2015.

Disclosure of Interest: None declared

DOI: 10.1136/annrheumdis-2017-eular.4499

\section{AB0986 FAMILY MEDITERRANEAN FEVER GENE MUTATIONS: A POORLY STUDIED CAUSE OF INTERMITTENT HYDRARTROSIS}

M. Espinosa Malpartida ${ }^{1}$, C. Barbadillo Mateos ${ }^{1}$, C. Ramos Giraldez ${ }^{1}$,

B.J. Flores Robles ${ }^{1}$, E. González Vioque ${ }^{2}$, C. Merino Argumanez ${ }^{1}$, M. Jimenez Palop ${ }^{1}$, J. Sanz Sanz ${ }^{1}$, H. Godoy Tundidor ${ }^{1}$, J. Campos Esteban ${ }^{1}$, J.L. Andreu Sanchez ${ }^{1}$, L.F. Villa Alcazar ${ }^{1}$, J. Mulero Mendoza ${ }^{1} .{ }^{1}$ Rheumatology;

${ }^{2}$ Biochemistry, Hospital Universitario Puerta de Hierro Majadahonda, Madrid, Spain

Background: Familial Mediterranean Fever (FMF) is an inherited autoinflammatory disorder caused by mutations in the MEFV gene encoding pyrine, characterized by recurrent episodes of fever and serositis. Some patients with FMF present incomplete penetrance of the disease and may manifest only as intermittent arthritis.

Objectives: Characterization of musculoskeletal clinical manifestations in patients with mutations of the MEFV gene in our hospital.

Methods: We retrospectively reviewed clinical records of patients with mutations detected in the Family Mediterranean Fever MEFV gene in our hospital from January 1, 2008 to October 1, 2016. We collected parameters such as age at diagnosis, age of onset Of the symptoms, sex, affected joints, other extra-articular manifestations and type of MEFV gene mutation. 